\title{
Os piqueniques das musas
}

\section{Ana Pais}

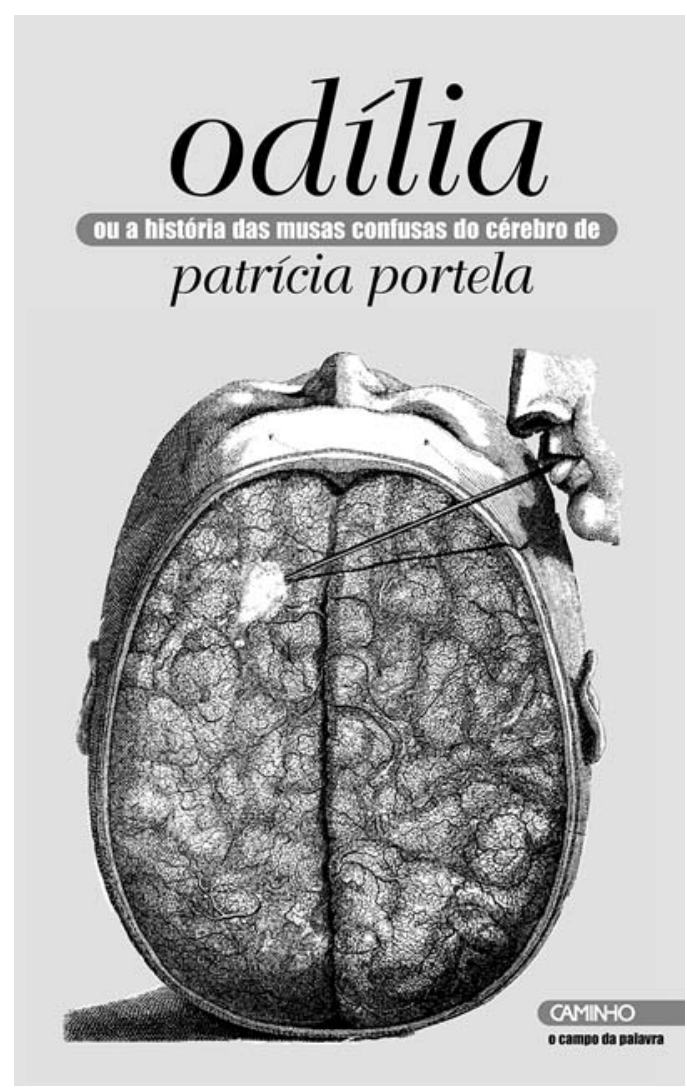

Até hoje ninguém conseguiu estar em dois tempos simultaneamente. 0 tempo, por interrupção, coincidência ou diferimento, tende a fragmentar-se e/ou sobrepor-se, criando inesperados entretempos. Pelo menos, é o que nos diz Odilia, a musa confusa que escolheu a autora Patrícia Portela para namorar. Por exemplo, este livro foi escrito num momento desses, um momento de naturezasmortas habitadas por musas que fazem piqueniques, um momento entre dois tempos. Para ser mais concreta, foi precisamente entre 2002 e 2007 que Patrícia Portela escreveu este texto. Tendo começado a desfiar o novelo desta história numa residência artística em Coed Hills (Pais de Gales), onde surgiram projecto e musas, seria apenas em Outubro de 2006 que Patrícia finalizaria uma etapa importante deste entretempo, data em que se estreava o espectáculo Odilia, no Festival Temps d'Image, no CCB. Um ano mais tarde, ei-la que regressa metamorfoseada em formato de livro, numa outra Odilia. Elucidativa e fundamental, esta metamorfose ajuda-nos a compreender a obra.

Duarante cinco anos, o projecto Odília - obras e entidade abstracta - tem sido uma musa incansável de

\author{
Patrícia Portela, Odília, Lisboa, Editorial \\ Caminho, 2007, 84 pp.
}

Patrícia, acompanhando todo um período de produção artística durante o qual os temas da espera, do tempo e da leitura a ocuparam incessantemente - para não dizer obsessivamente, pois é nisso que os artistas se distinguem dos que gostariam de ser artistas.

No ano seguinte ao primeiro esboço e apresentação pública do projecto Odília no País de Gales, Patricia estreava Wasteband, peça mascarada de sessão de lançamento de espectáculo do futuro, isto é, um espectáculo produzido numa "faixa de tempo perdido"1 por meio do virtualómetro, dispositivo que mede e mistura as ideias livremente associadas por cada espectador, produzindo tantos espectáculos individuais quantos os espectadores. No fundo, o que ali acontecia era o contar de uma história que falava sobre a passagem do tempo, e por isso não se passava literalmente nada... Adivinhava-se já a centralidade que a narrativa evidenciaria gradualmente no trabalho da autora.

Em 2004, as temáticas da leitura e da imagem ganhavam espessura através de um homem plano com problemas existenciais, que não descansou enquanto não raptou o público inteiro de um teatro para o manter entretido e poder ser visto continuamente, e, portanto, existir no mundo tridimensional. Este era o pretexto da Trilogia Flatland, cujos episódios estreariam até 2006, surpreendendo-nos com a saga de uma personagem que, claro, vive num livro e se debate com os desafios da vida no espaço, com volume e movimento.

Com a Trilogia, Patrícia conquista uma notoriedade pública significativa, tanto por parte dos media quanto por parte da crítica. Para tal, contribuiu não só a inteligência da proposta estética como também o seu modo caracteristico de abordar questões cruciais da contemporaneidade - a condição de existência vigiada, 0 simulacro das imagens, o terrorismo - retirando-Ihe 0 peso da complexidade que lhes é inerente por via de uma força lúdica, de um humor delirante e delicado, reconhecivel em Odilia. Aliás, na linhagem directa de Flatland, obra em que a narrativa é apresentada como um poder criador à disposição de todas as realidades, Odilia regressa das remotas origens sob a forma de um espectáculo, requerendo do seu público - estipulado para maiores de 8 anos - a disponibilidade de se oferecer à experiência do acontecimento. Odília viria explicar de onde vêm e como surgem as ideias com que lemos o mundo e o tornamos real.

0 facto de hoje se lançar em livro em nada se deve à típica - e legítima - ambição do dramaturgo de publicar 
a sua obra, habitualmente, com o intuito de permitir que outros a eternizem no palco. Neste sentido, este livro não é o texto do espectáculo Odília, nem tão-pouco é um texto dramático; ele é... um livro, uma novela, uma outra Odilia, uma conversa entre uma musa e um leitor, embora, obviamente com base no mesmo material do espectáculo. Não é a primeira vez que Patrícia publica um texto seu levado à cena, mas é a primeira vez que ele se constitui como um objecto autónomo, facto esse, a meu ver, decorrente do culminar de um periodo de questionação profundo sobre a escrita e o papel desta nos espectáculos que produz.

No entretempo de cinco anos, Patrícia fez a corte à Literatura sob a forma de teatro. $E_{1}$ do mesmo modo que assume a responsabilidade artistica pela globalidade de cada projecto - o que não é dificil, sendo alguém com uma polivalência notável: nos figurinos, nos cenários, no vídeo, no texto e na encenação -, assim também neste livro, Patrícia explora uma visão de conjunto do objecto, particularmente no que respeita à articulação do texto com as notas, com as ilustrações e com o grafismo. Partindo da noção de escrita enquanto linha, um fio de novelo que liga letras a letras, silabas a silabas, palavras a palavras, frases a parágrafos, parágrafos a páginas, parágrafos a desenhos e a vozes, um fio único fabricador de infinitos tecidos narrativos (ou seja, de textos). Patrícia sublinha a relação semântica entre tecer e escrever, em tudo pertinente para contar a história de uma musa confusa, muito parecida com Ariadne, desfiando a sua roupa pelo labirinto dos dias (e que no espectáculo dá lugar a um magnífico figurino), acompanhada por Penélope que desde a Antiguidade simboliza a espera através do tecido que desfaz e refaz enquanto Ulisses não chega e, apesar de ser uma musa ao contrário sempre acaba por inspirar o poeta... a escrever. Encontramos um exemplo muito claro na escolha dos títulos dos capítulos: cada frase, sendo título, é também já o início do primeiro parágrafo do capítulo, cosido e ligado pelo fio de Ariadne.

A qualidade dramatúrgica do trabalho da Patricia, ou seja, o seu cuidado e coerência nas relações de sentido que tece, mantém-se intacta no domínio literário.

Particularmente enriquecida pela sua prática cénica, a sua singularidade escrita reveste-se de um carácter performativo veiculado, quer pelas vozes que se entrecruzam na história (narrador, Odilia, editor, tradutor, autor), quer pela estutura do texto elaborado como se fosse uma "conversa ao vivo", como se estivesse realmente a acontecer à medida que o leitor lê o livro. Por outras palavras, como se o tempo da leitura exigido fosse um entretempo mágico, um "durante" (conforme explica a musa), ele próprio uma naturezamorta habitada por musas que fazem piqueniques. Como seria de esperar, esta Odilia em papel tem uma clara dimensão teatral.

Procurando estabelecer uma "con-vivência" real entre o universo de Odília e o leitor, Patrícia recorre, obviamente, ao seu saber acumulado para proporcionar uma experiência de tempo, inerente às artes de palco, convertida aqui na transformação da leitura num "acontecimento" no tempo. Dir-me-ão que todos os livros têm esta potencialidade porque precisamos sempre de imaginação e de tempo para os ler; é certo, mas nenhum tem este carácter acentuado de acontecimento, como se um livro acontecesse connosco; esta experiência particular de conceber a leitura pode até levar-nos a pensar se será possivel tornarmo-nos livro, se será possivel acontecermos com ele à medida que ele acontece no entretempo? No que seria o evento mais louco do mundo, Odila seria capaz de nos transportar para dentro da história, partilhando da experiência única de que o teatro se faz.

Do ponto de vista da estrutura do texto, as notas explicativas "durante", que iniciam e fecham o livro, para além de nos maravilharem em absoluto, dão voz à musa para "falar" directamente com o leitor, para o colocar do lado de cá da história, promovendo uma ilusão de proximidade. Inclusivé quando o narrador toma a palavra, Odília não se contém, está sempre ali ao lado, pronta para interromper várias vezes, ou ao poeta, o que, a par das muitas referências espaciais, resíduos intencionais da memória do espectáculo - tal como no caso da nota de rodapé em que se sugere comer uma laranja para melhor compreender a definição de musa confusa, acção que acontecia no espectáculo de uma forma particularmente deliciosa -, transportam o leitor para um espaço onde o evento se desvanece para acontecer, onde uma musa e um leitor "se começam".

Mas há outro aspecto fundamental e determinante para a construção desta experiência: todo o cuidado dramatúrgico na composição gráfica das páginas promove a criação de uma temporalidade porque destaca o aspecto sonoro das palavras - os tons, a altura ou o uso de onomatopeias. Como o som tem a capacidade de nos colocar no centro perceptivo do seu próprio acontecimento, assim também esta evocação gráfica da voz nos conduz ao coração da história. Tudo em Odilia nos faz respirar como se estivessemos ao lado de uma musa, partilhando com ela um espaço e um tempo, antes ou depois de acontecer realmente alguma coisa. Nos seus incontáveis espaços em branco, nos desenhos, nos intervalos, o grafismo recria gritos, vozes ou ecos de palmas de formigas arquitectando um efeito da página sobre a nossa experiência de tempo e, consequentemente, sobre a nossa leitura. Mais ainda, a experiência de tempo desejada neste livro é a de um tempo feliz, não porque não haja infortúnios e contratempos (afinal, Odilia está desempregada e perde o seu grande amor assim que o encontra), mas porque durante essa experiência de leitura temos tempo para estar, para pensar e para acontecer; porque a autora não nos quer mostrar ou ensinar nada, antes nos deixa escolher: porque podemos habitar um espaço com outros e sentir que pertencemos a uma comunidade, também essa virtual; porque podemos permitir-nos ser tocados por palavras e sensações, porque podemos abandonar-nos ao deslumbramento e à redescoberta de um tempo eterno e irrepetivel, como se fosse a primeira vez.

Nova lorque, 1 de Outubro de 2007 